ÉGYPTE

monde arabe

\section{Égypte/Monde arabe}

30-31 | 1997

Les visions de l'Occident dans le monde arabe

\title{
Les visions de l'Occident dans le monde arabe : Préface
}

\section{Marcello Pacini}

\section{(2) OpenEdition}

12 Journals

Édition électronique

URL : https://journals.openedition.org/ema/1592

DOI : 10.4000/ema.1592

ISSN : 2090-7273

\section{Éditeur}

CEDEJ - Centre d'études et de documentation économiques juridiques et sociales

\section{Édition imprimée}

Date de publication : 30 septembre 1997

Pagination : 9-11

ISSN : 1110-5097

\section{Référence électronique}

Marcello Pacini, «Les visions de l'Occident dans le monde arabe : Préface », Égypte/Monde arabe [En ligne], 30-31 | 1997, mis en ligne le 08 juillet 2008, consulté le 07 juillet 2022. URL : http:// journals.openedition.org/ema/1592 ; DOI : https://doi.org/10.4000/ema.1592

Ce document a été généré automatiquement le 7 juillet 2022.

Tous droits réservés 


\title{
Les visions de l'Occident dans le monde arabe : Préface
}

\author{
Marcello Pacini
}

1 La rencontre entre cultures devient à l'heure actuelle l'un des traits les plus significatifs du monde contemporain, favorisée par une interdépendance croissante entre les différentes aires régionales et les différents pays, ainsi que par la facilité et l'intensité des communications.

2 Cependant, il ne s'agit pas d'une rencontre abstraite, mais d'une rencontre déterminée de façon multiple par l'intermédiaire d'une pluralité d'acteurs et de «lieux». La perception de l'« autre » est ainsi filtrée au travers de perspectives diverses. À chaque fois, selon les acteurs impliqués, certains des éléments propres à une culture et à une société sont sélectionnés et transmis comme des traits particulièrement caractéristiques, qui deviennent les critères de lectures bien plus générales. Ce processus complexe donne naissance à la diffusion d'une connaissance de l'«autre » construite à l'aide de stéréotypes et d'images souvent contrastées, mais pareillement répandues et dans un rapport dialectique les unes aux autres.

La Méditerranée, qui constitue une aire géographique à la cohérence et à l'unité propres, est perçue depuis des siècles comme la frontière entre deux civilisations et deux mondes l'Occident européen et chrétien et l'Orient arabo-musulman. Pendant des siècles, les perceptions réciproques des sociétés qui se sont développées sur ses deux rives ont été caractérisées par un sentiment d'altérité, développé et exprimé par l'intermédiaire des "visions" réciproques. Ce sentiment, qui n'a pas empêché l'existence de contacts multiples et continus - commerciaux, politiques, culturels, ces derniers réservés principalement aux élites - n'en a pas pour autant disparu, se transformant et se réélaborant tout au plus grâce à ces mêmes contacts.

4 La diffusion et la diversification à l'intérieur desquelles les contacts et les images réciproques prennent forme n'ont jamais été plus importantes qu'à l'époque contemporaine. Les contacts et les visions véhiculés par les expériences des élites culturelles ou politiques, ne tiennent plus l'exclusive, même s'ils conservent, aujourd'hui encore, un rôle spécifique. D'une manière plus précise, il s'agit désormais 
de rencontres et de représentations qui se développent à partir de quantité de « lieux » et de groupes sociaux différenciés.

$5 \mathrm{Si}$, jusqu'au début du siècle, le journal tenu par le voyageur arabe est l'un des témoins privilégiés de la "vision de l'Occident", aujourd'hui on se trouve par contre en présence de nombreux "médiateurs» qui transmettent des informations sur l'Occident, sur ses dynamiques sociales, culturelles, politiques et qui répandent ses techniques et ses objets. De ce processus différencié naissent des images et des visions de l'«autre »-dans ce cas, les sociétés occidentales -, souvent constituées de façon sélective, et filtrées au travers du prisme des attentes, des préconceptions et des objectifs qui renvoient aux différents rôles que les sujets, individuels ou collectifs, entendent jouer dans leurs propres sociétés arabes.

Ces visions diversifiées, multiples, changeantes, influencent considérablement la connaissance de l'«autre » et le rapport à lui. Construites souvent sur des stéréotypes, parfois d'ailleurs diamétralement opposés (l'Occident comme idéal utopique ou comme exemple d'immoralité et de barbarie), les visions de l'Occident n'arrivent généralement pas à transmettre une connaissance réelle, approfondie et diversifiée de l'Europe contemporaine et de sa complexité. Elles ont toutefois une influence importante sur la perception diffuse dans les sociétés arabes de la culture et des sociétés occidentales et forment ainsi une sorte de "précompréhension", diversement structurée et redéfinissable selon les circonstances, dont il faut tenir compte si l'on veut promouvoir des relations culturelles intelligentes et fécondes entre les sociétés des deux rives de la Méditerranée. Un propos analogue pourrait d'ailleurs s'appliquer aux «visions du monde arabo-musulman » en Europe.

7 Depuis une décennie environ, la Fondation Giovanni Agnelli prend une part active au dialogue culturel euro-méditerranéen, par des recherches et des initiatives ayant pour but de diffuser en Italie et en Europe une connaissance diversifiée et approfondie des dynamiques culturelles, politiques et sociales à l'œuvre dans les sociétés arabes contemporaines. Après avoir consacré des recherches aux transformations politiques et sociales, à l'urbanisation, ainsi qu'au pluralisme confessionnel interne aux sociétés arabes, la Fondation a décidé de promouvoir, en collaboration avec le Centre d'études et de documentation économique, juridique et sociale du Caire (Cedej), cette recherche sur les «visions de l'Occident dans le Monde arabe ». Le choix du thème place cette étude dans une perspective particulière, tout en demeurant cohérent par rapport au plan d'ensemble des recherches de la Fondation. Dans ces dernières, le dessein est de comprendre les dynamiques sociales, politiques et culturelles des sociétés arabes, en relation avec les problèmes contemporains et les transformations en cours. Les recherches sur la situation des communautés arabes chrétiennes permettent de saisir, à partir d'un cas concret, les modèles de société vers lesquels tendent les différents courants et les différentes composantes sociales, religieuses et politiques. Il s'agit, si l'on veut, de voir dans quelle mesure la différence confessionnelle constitue une altérité et comment cette dernière se traduit en termes sociaux, juridiques et politiques.

8 La recherche sur les visions de l'Occident est en quelque sorte complémentaire des précédentes. Elle se propose en effet d'étudier, non pas les dynamiques sociales et politiques des sociétés arabes contemporaines, mais la manière dont, à la faveur de ces dynamiques, sont élaborées, diffusées et transformées les images de cet Occident qui est et continue d'être, dans l'imaginaire collectif et depuis des siècles, l'« autre » par 
excellence, avec toutes les attributions positives et négatives attachées à cette perception. Cette recherche, nous l'avons dit, s'est proposé d'analyser une multiplicité de lieux, de sujets, d'usages à travers lesquels tenter de saisir les images et les représentations de l'Occident, sans oublier de mettre en évidence les situations sociales spécifiques dans lesquelles sont insérés les différents acteurs qui élaborent ces images et ces discours ou qui pratiquent ces usages. Il en ressort un tableau composite, parfois fragmentaire, souvent conditionné par des utilisations idéologiques ou par les situations socioculturelles concrètes des différents groupes ou composantes sociales qui se réfèrent à l'Occident ou à ses pratiques. Beaucoup d'Européens ne se reconnaîtraient probablement pas tout à fait dans l'ensemble contrasté des visions répandues, et trouveraient à chaque fois une image de soi généralisée ou basée sur quelques éléments sélectionnés et transformés en stéréotypes. C'est là un processus typique de perception de l'autre, qui se développe dans toutes les sociétés. Mais pour promouvoir une connaissance réciproque approfondie, plus complète et plus complexe, il est indispensable de connaître et de prendre en compte les "précompréhensions " nées des représentations, même si l'on sait que l'imaginaire, en tant que réalité anthropologique et socioculturelle, jouera toujours un rôle important dans ces connaissance et compréhension mutuelles, surtout s'il s'agit d'ensembles sociaux appartenant à des contextes culturels différents. Il est donc fondamental que ces processus, par lesquels naissent représentations, stéréotypes et préjugés, deviennent objets d'analyse et d'étude à l'intérieur d'un projet plus vaste de dialogue culturel sérieux.

\section{AUTEUR}

\section{MARCELLO PACINI}

Directeur de la Fondation Giovanni Agnelli 